\title{
Assessment of Remotely Sensed Digital Elevation Models (DEMs) Compared with DGPS Elevation Data and Its Influence on Topographic Attributes
}

\author{
Moawad Badawy Moawad ${ }^{1 *}$, Ahmed Omar Abd El Aziz² \\ ${ }^{1}$ Department of Geography, Faculty of Arts, Ain Shams University, Cairo, Egypt \\ ${ }^{2}$ Parsons Corporations, Riyadh, Saudi Arabia \\ Email: *moawad@outlook.com
}

How to cite this paper: Moawad, M.B. and El Aziz, A.O.A. (2018) Assessment of Remotely Sensed Digital Elevation Models (DEMs) Compared with DGPS Elevation Data and Its Influence on Topographic Attributes. Advances in Remote Sensing, 7, 144-162.

https://doi.org/10.4236/ars.2018.72010

Received: March 17, 2018

Accepted: June 26, 2018

Published: June 29, 2018

Copyright $\odot 2018$ by authors and Scientific Research Publishing Inc. This work is licensed under the Creative Commons Attribution International License (CC BY 4.0).

http://creativecommons.org/licenses/by/4.0/

\begin{abstract}
Accuracy and quality of DEM are of a great interest for a wide range of applications. In this study, quality of ASTER GDEM and SRTM DEMs were assessed in comparison with DGPS measurements. Impact of DEM resolution upon the accuracy of terrain representation and topographic attributes was also discussed. The study deduced that vertical error has a strong effect on error propagation and this highly obvious in higher elevations as the absolute standard error (SE) ranges between is $\pm 0-2.5$ and $\pm 0-2.4 \mathrm{~m}$ for ASTER GDEM and SRTM respectively. This is reflected on slope and aspect as the vertical errors increase and uncertainty is relatively high in flat and low areas. Error propagation in low lands influenced drainage extraction and resulted in isolated and truncated water courses.
\end{abstract}

\section{Keywords}

SRTM, ASTER GDEM, RTK System, Error Assessment, Topographic Attributes

\section{Introduction}

Digital Elevation Models (DEMs) provide a full 3d perspective-view of an elevation surface. DEMs are a corner-stone for a wide range of geoscience studies such as: hydrological modeling and flood simulation, civil engineering, soil and ecological studies, geomorphological mapping, geohazard assessment, etc.

DEMs are acquired from satellite remote sensing (optical or radar imaging systems), photogrammetry analysis, topographic maps by digitizing contour lines and spot heights, and site survey. Structure of the data is usually organized 
in a square digital elevation grid, triangular irregular network (TIN), and set of digital line graph contours or random points. Satellite remote sensing constellations in specific provide vast amounts of DEM data, ranging from global $(\sim 1 \mathrm{~km}$ e.g., USGS GTOPO30) to a very fine scale ( 1 - 2 m e.g., GeoEye-1, WorldView-3). For each application, decisions are made on which elevation data to use driven by cost, resolution and accuracy [1]. However, free of charge DEMs (e.g., SRTM, ASTER GDEM) are wide-spread. These data sets provide a spectacular new window on the earth's landforms, but users must understand its limitations [2], since they suffer from a large number of errors such as gridding and contour artifacts, odd values (i.e., pits and peaks), and incongruity with other elevation data sources.

DEM errors are generally categorized as either systematic, blunders or random [3]. Systematic errors result from procedures or systems of DEM generation and cause bias or artifacts in the final product such as vertical elevation shifts, fictitious features, and improper interpretation of terrain surfaces due to effects of trees, buildings, and shadows.

Blunders errors are vertical errors which exceed the maximum absolute error permitted. They caused by misreading contours, transposing numeric values, erroneous correlations, or careless observations during data collection process. After removing systematic and blunders errors, the remaining errors are known as random errors. They result owing to accidental and unknown combinations of causes beyond the control of the observer [3].

These various errors often produce cell or groups of cell values that are artificially lower/higher in altitude than their surrounding cells [4]. Even if errors are small, they can propagate through to large errors in such terrain models and inevitably in the final application [5].

Since DEM quality is influenced by several factors, e.g., sensor types, algorithm, terrain type, grid spacing and characteristics [6], DEM accuracy is at stake [7]. DEM accuracy and quality have been reported in many works based on the estimation of the root mean square error and statistical analysis in comparison with other elevation data or field data (e.g., [7]-[16]).

The main objective of this work is to assess the quality of ASTER GDEM (the Advanced Spaceborne Thermal Emission and Reflection Radiometer) and SRTM DEMs (Shuttle Radar Topography Mission) in comparison with in situ DGPS (Differential Global Positioning System) elevation data. This would reveal the impact of DEM resolution upon the accuracy of terrain representation and topographic attributes in a relatively low relief area. The results would be valuable to determine the appropriate DEMs for a particular application, improve topographic attributes and drainage extraction, and contribute to the previous works concern the assessment of ASTER GDEM and SRTM DEMs quality.

\section{Study Area}

The study area lies on the eastern side of the River Nile between latitudes $26^{\circ} 04^{\prime} 30^{\prime \prime} \mathrm{N}$ to $26^{\circ} 13^{\prime} 30^{\prime \prime} \mathrm{N}$ and longitudes $32^{\circ} 45^{\prime} \mathrm{E}$ to $33^{\circ} 10^{\prime} \mathrm{E}$ (Figure 1 ). It covers 

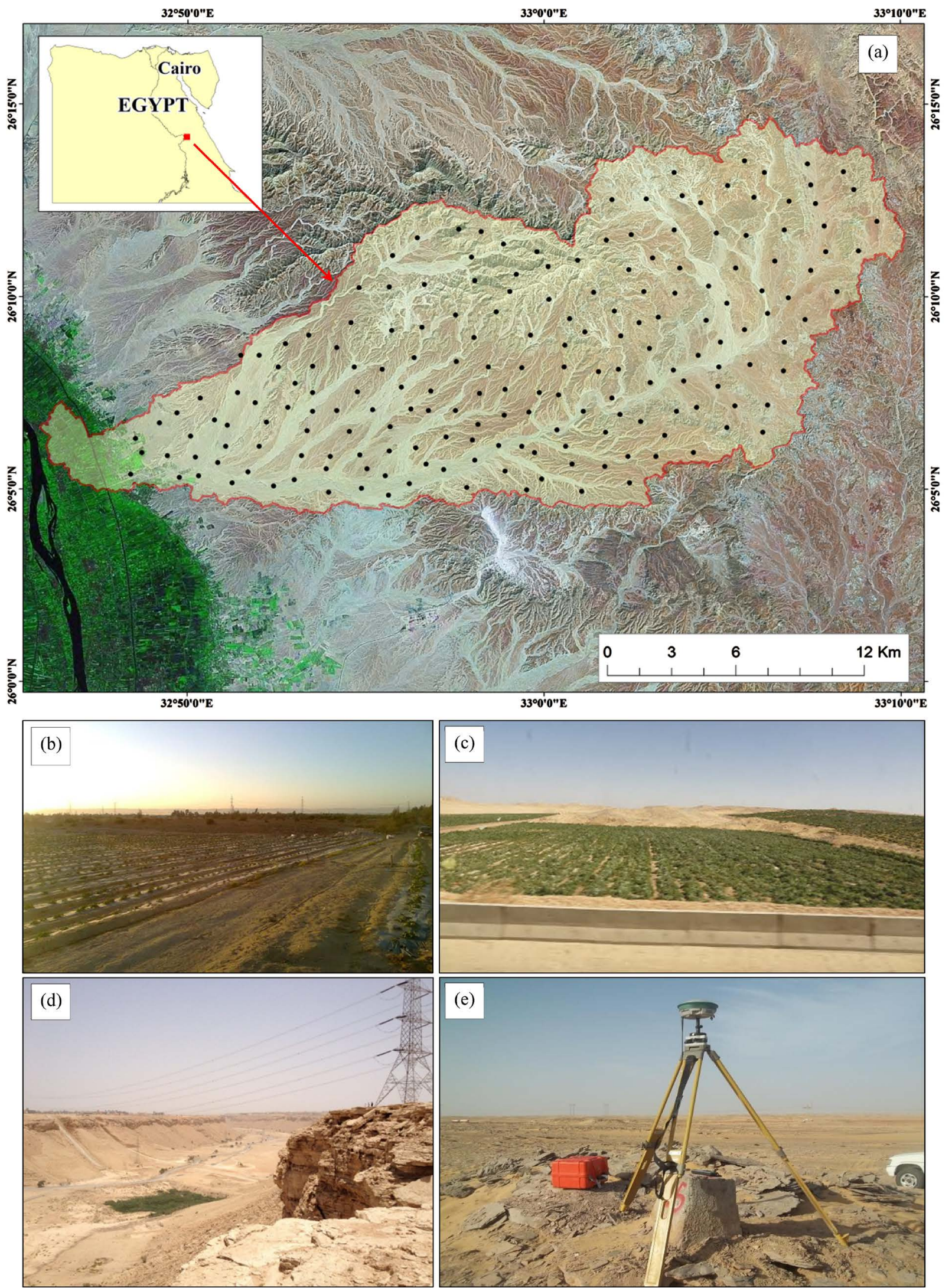

Figure 1. (a) Location of study area with GPS measurements; (b)-(d) Land reclamation and building infrastructure; (e) GPS in situ base-station with Real Time Kinematic (RTK) system. 
$\sim 420.5 \mathrm{~km}^{2}$ and characterized by relatively low relief and marked by the mouth of Wadi (=dry valleys) El Serai (=mystery) that drains the north-east and south-east highlands $(+600 \mathrm{~m})$ and debouching into the Nile Valley $(+72 \mathrm{~m})$. This area has been selected because it is a promised area for land reclamation and agriculture development, so it is interspersed by many new villages and infrastructures although it is threatened by flash flood occurrence from the poorly ungauged Wadi El Serai. The area is covered by a great thick of sedimentary rocks (sand stone, shale and calcareous rocks), ranging in age from Cretaceous to Pliocene times. The sedimentary rocks are overlaid with loose and/or consolidated Quaternary deposits (alluvial, sand, gravels and Nile deposits). Land reclamation is based mainly on the shallow aquifers within the Quaternary alluvial sediments (10 - $90 \mathrm{~m}$ depth).

\section{Data and Methods}

In this study, we used different data types and methods of analysis (Figure 2), which can be summarized as follows:

\subsection{Specifications of ASTER GDEM}

ASTER (Advanced Spaceborne Thermal Emission and Reflection Radiometer) GDEM version2 is a product that is generated from a pair of ASTER Level-1A images. This Level-1A input includes bands-3N (nadir) and -3B (after-viewing) from the visible near infra-red (NIR) telescope's along-track stereo data that is acquired in the spectral range of 0.78 to $0.86 \mu \mathrm{m}$. The absolute vertical accuracy of the GDEM-2 mean error is -0.20 meters on average with accuracy of 17

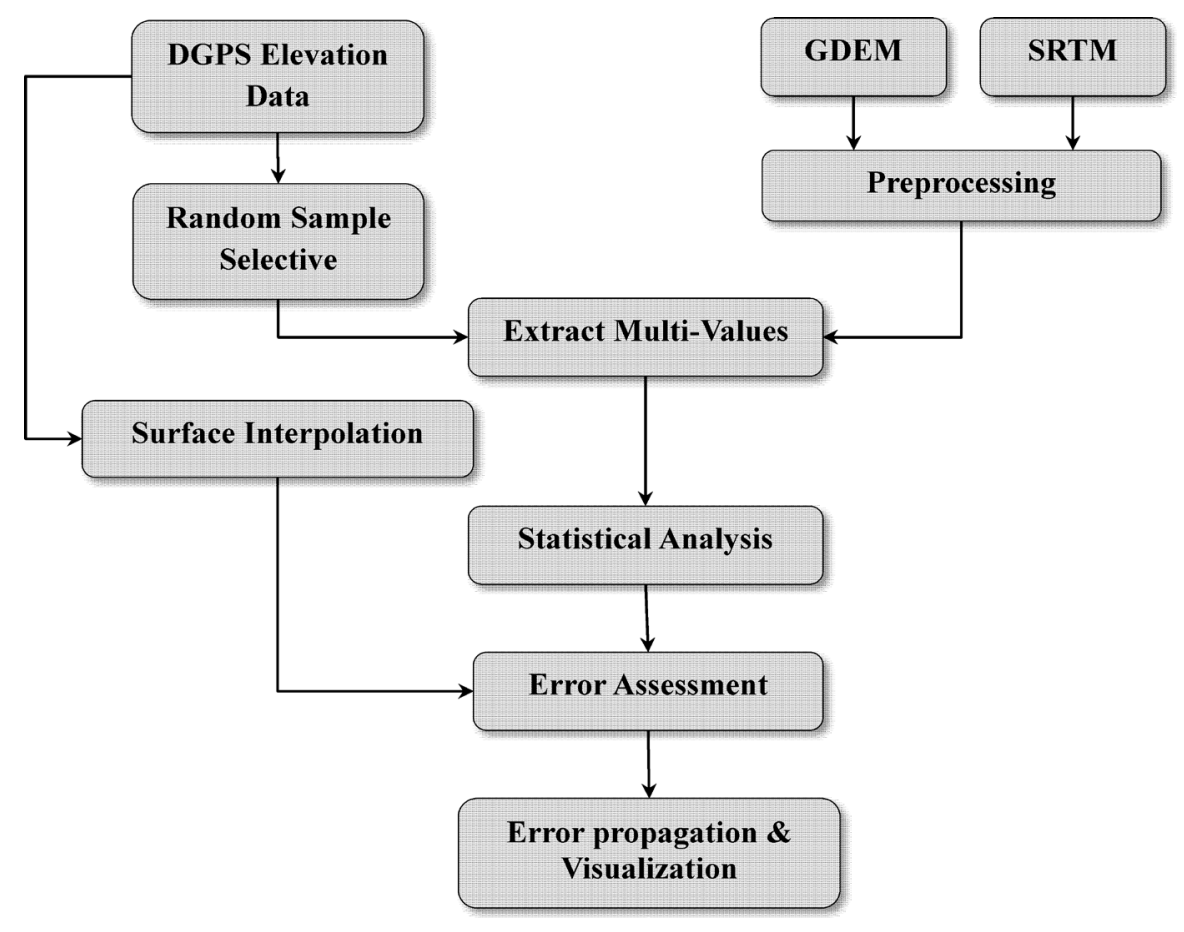

Figure 2. Study scheme. 
meters at the $95 \%$ confidence level, which is a significant improvement compared to the GDEM v1 mean error of -3.69 meters [17]. Number of voids and artifacts noted in GDEM v1 were substantially reduced in GDEM version2. ASTER GDEMs are generally expected to meet map accuracy standards for scales from 1:50,000 to 1:250,000. DEMs are available for download from NASA's EOS data archive and Japan's Ground Data System

(http://earthexplorer.usgs.gov). ASTER GDEM image number: ASTGTM2_N26E032 was downloaded for the study area (Figure 3).

\subsection{Specifications of SRTM Data}

The Shuttle Radar Topography Mission (SRTM) used the single-pass Interferometric Synthetic Aperture Radar (InSAR) technique to determine a nearly worldwide height model. The space shuttle carried in two radar antenna combinations
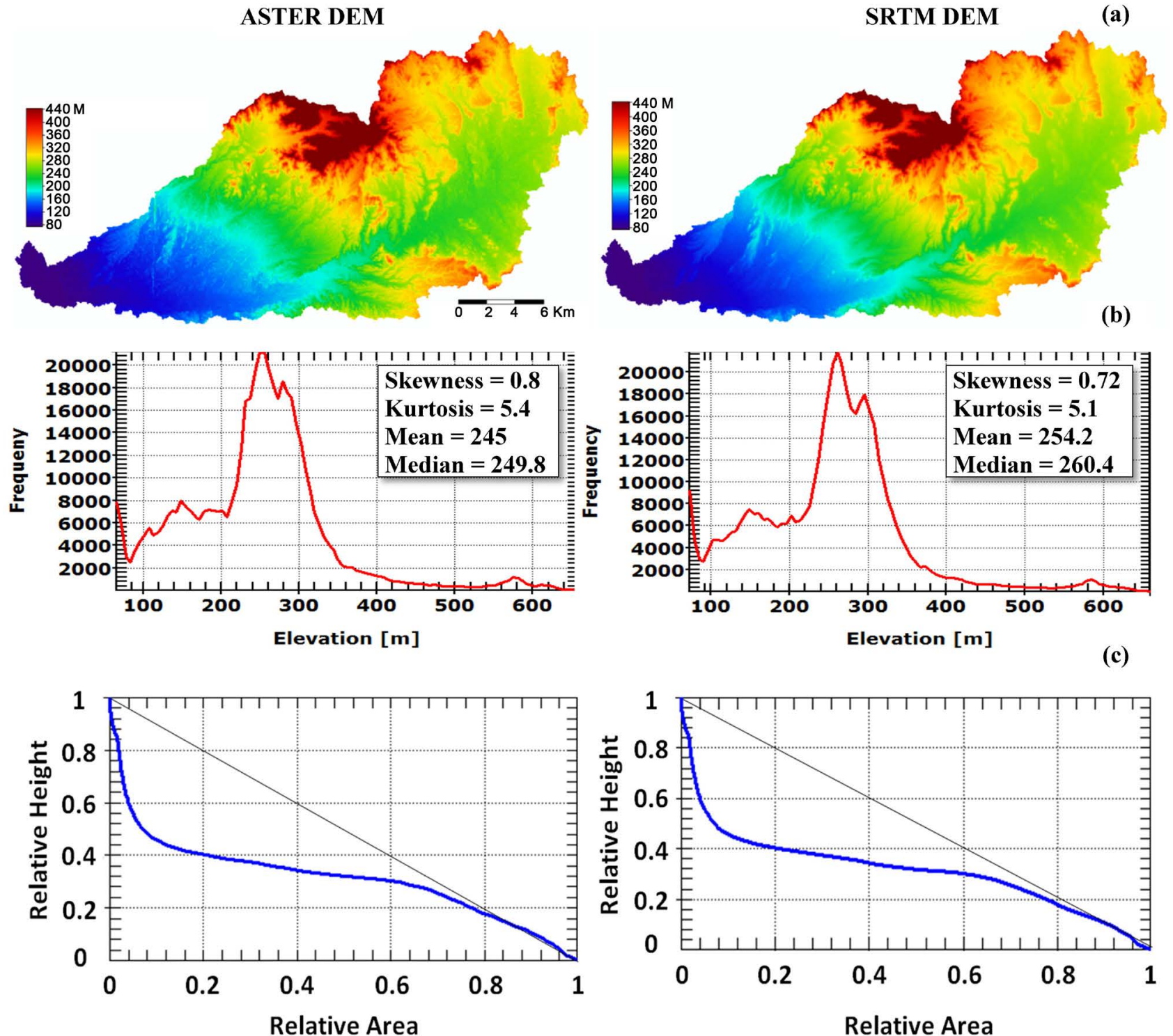

Figure 3. (a) Digital elevation models of Wadi El Serai; (b) Elevation histogram; (c) Hypsometry. 
for C-band and X-band. The C-band used the scan-SAR mode with a swath width of $228 \mathrm{~km}$; while the German-Italian X-band was limited to a swath width of $45 \mathrm{~km}$. C-band was preferred for this study because it gives a continuous coverage nearly without gabs, while SRTM X-band has large gaps between the covered areas ( 1 arc second or $\sim 30 \mathrm{~m}$ ) and therefore it is not used in this study.

The mission obtained elevation data on a nearly global scale of $90 \mathrm{~m}$ ground resolution for SRTM v2 and $30 \mathrm{~m}$ for SRTM v3. The elevation data representing the visible land surface (Digital Surface Model) including vegetation and buildings if exist. In this study, SRTM version2 image No. SRTM3N26E032V2 (Figure 3) was used because SRTM v3 was achieved by filling the void with elevation data obtained from ASTER GDEM version 2 and USGS GMTED 2010 elevation model or the USGS National Elevation Dataset (NED) [18]. Image data were then resampled to $30 \mathrm{~m}$ to be compatible with the ASTER GDEM. SRTM data can be downloaded for free via the USGS through earth explorer web site (http://earthexplorer.usgs.gov). The nominal vertical accuracy of the SRTM DEMs v2 is $16 \mathrm{~m}$ and horizontal accuracy is $20 \mathrm{~m}$ at the $90 \%$ confidence level [19]. X-band data suffers from a severe data missing problem and was therefore not used in this study.

\subsection{Specifications of DGPS Data}

GPS (Global Positioning System) is a satellite-based system used to locate positions on the earth surface for 24 hours/day. Differential Global Positioning System (DGPS) in specific is an enhanced GPS system provides differential corrections to GPS receiver based on a static reference station at a known location. Ever since GPS is rapidly adapted for surveying as it provides positions in three dimensions $(\mathrm{x}, \mathrm{y}, \mathrm{z})$. Data accuracy ranges from few millimeters to few meters $(\sim 15 \mathrm{~m})$ depending on equipment and procedures applied to the process of data collection.

In this study, we used Sokkia GRX2 receiver that provides 226 and superior antenna quality with Real Time Kinematic (RTK) system (Figure 1). RTK system uses a single static base station receiver and a number of mobile units. The static base station was established in unobstructed view of the sky above $10-15$ degree for good satellite visibility and to provide reliable correction messages to signal delays. The base station was set up in on the ground and then working out to record GPS data over a span of time.

The base station re-broadcasts the phase of the carrier that it observes (measurements and coordinates) to the mobile receivers. The built-in software in a rover receiver combines and processes the GPS measurements collected at both the base station and the rover receivers to obtain the rover coordinates [20]. This moving mode allows the units to calculate their relative position precisely with typical nominal accuracy of $10 \mathrm{~mm},+1 \mathrm{ppm}^{1}$ horizontally and $15 \mathrm{~mm}+2 \mathrm{ppm}$ vertically. Location accuracy of approximately $50 \times 50$ meters regular grid was obtained with a vehicle tracker DGPS receiver for 81,454 points covering the

${ }^{1}$ Parts per million: $1 \mathrm{ppm}$ corresponds to a $1 \mathrm{~mm}$ error over $1 \mathrm{~km}$. 
study area based on RTK system, with a density of 193.7 points $/ \mathrm{km}^{2}$.

\subsection{Preprocessing}

ASTER GDEM and SRTM tiles were obtained in a tiff format using geographic coordinate system (GCS) based on the Word Geodetic System 1984 (WGS84) horizontal datum and the EGM96 vertical datum. Tiles projection was then transformed into UTM zone 36 using WGS84 datum as default vertical datum to be in accord with the DGPS data and to compute the relative heights. Additional processing was required for noise reduction such as fill gabs to eliminate random sinks and peaks. Such random noises are a result from the technical procedures in the DEM production processes and highly correlated with coarser resolution DEMs. A sink is a cell surrounded by higher elevation values and therefore it has undefined drainage direction or internal drainage. A peak is a cell that is extremely higher than its neighbors. In this study, the arithmetic mean filter (low pass filter $3 \times 3$ ) was applied to all DEMs to smooth datasets and remove possible outliers [12] [21] [22].

Elevation histograms reveal nonsymmetrical or positive or right skewed distribution with long right tail towards higher elevations. In such case mean and median are not equal. Skewness ranges between $0.8-0.72$ for ASTER GDEM and SRTM, respectively.

Kurtosis analysis reveals that elevation histograms also have more peaks means that a distribution also has fatter tails because of extreme outcomes compared to a normal distribution. Kurtosis ranges between $5.4-5.1$ in the same order.

Plotting relative area versus relative height (hypsometric representation) manifests that relative low lands are the most dominant within the basin. They constitute $91.7 \%$ of the basin area, range in elevation between $80-320 \mathrm{~m}$ (a.s.l) and only $8.3 \%$ of the basin area ranges in elevation between $320-660 \mathrm{~m}$ (a.s.l). This confirms that the elevation data reveals positive skewed since it tends to concentrate towards the lower values reflecting old stage of denudation since the area below the hypsometric curve (hypsometric integral $=\mathrm{HI}$ ) is close to zero and $\mathrm{HI}$ equals 0.36 [23].

\section{Error Assessment}

Quantifying vertical accuracy was normally achieved by comparing the DGPS points to the nearest SRTM/ASTER GDEM Pixel value. For the purposes of model validation and statistical analysis, stratified randomly 100 DGPS elevation points were selected with their explicit $\mathrm{x}$ and $\mathrm{y}$ coordinates. Multi-value extraction tool in ArcGIS was used to extract cell values of the specified DGPS points from the ASTER GDEM and SRTM DEMs. Therefore, cell values were extracted for each input raster and a new field contains the cell values for each input raster was appended to the input point feature class.

Then DEM validation was represented by using statistical measurements 
namely elevation error $\left(\mathrm{Z}_{\mathrm{dif}}\right)$, mean error $(\mathrm{ME})$, Standard deviation error $\left(\mathrm{STD}_{\text {err }}\right)$, Root mean square error (RMSE) (Table 1). The vertical accuracy of the two DEMs was calculated from the differences corresponding between the value of the DEM pixel and the reference GPS elevation points. Elevation error was calculated whereas the positive differences denote that DEM values exceed the reference GPS elevation points, while negative differences denote that DEM values are below the reference GPS elevation points. Maximum, minimum and average errors were calculated from the elevation error. STD is used to measure the spread of data around the mean, while RMSE is used to measure the error of prediction based on distance between some values. STD and RMSE reveal surface quality and offer perception into the distribution of deviations on the side of the mean value [16] [24] [25].

Quantile-Quantile plots (Q-Q plots) based on the normal distribution are created for visual examination. The $\mathrm{Q}-\mathrm{Q}$ plots of the reference data versus DEMs depict that the DEMs data are greatly undulated around the best fit linear relationship. That means DEMs data are mostly higher than the corresponding reference GPS data and to some extent other point samples are relatively lower than the reference data (Figure 4) and the sample data are not normally distributed. However, spatial autocorrelation analysis reveal significant relationship between the data sets $\left(r^{2}=0.74\right)$.

Table 2 shows that the overall absolute vertical accuracy; expressed as the root mean square error (RMSE) is 75.8 for ASTER GDEM and 79.2 for SRTM. Therefore, ASTER GDEM and SRTM DEMs are less accurate than the reference data. This is not surprising, giving into account that the reference data representing an explicit $\mathrm{x}$ and $\mathrm{y}$ point, while remotely sensed DEMs have a ground resolution of 30 and $90 \mathrm{~m}$ for ASTER GDEM and SRTM, respectively.

\section{Error Propagation and Visualization}

Effects of random errors in DEM for terrain analysis have been investigated using analytical and numerical error propagation techniques. Among the earliest works in DEM error propagation analysis, solutions for calculating standard

Table 1. Description of the validation statistical methods

\begin{tabular}{ccc}
\hline Statistical Method & Description & Equation No. \\
\hline Elevation Error & $Z_{d i f}=Z_{D E M}-Z_{G P S}$ & Equation (1) \\
Mean Error & $M E=\frac{\sum_{i=1}^{n} Z_{d i f(i)}}{n}$ & Equation (2) \\
Standard Deviation & $S T D_{e r r}= \pm \sqrt{\frac{\sum_{i=1}^{n}\left(Z_{d i f(i)}-M E\right)^{2}}{n-1}}$ & Equation (3) \\
Root mean square error & $R M S E=\sqrt{\frac{\sum_{i=1}^{n}\left(Z_{d i f(i)}\right)^{2}}{n}}$ & Equation (4) \\
\hline
\end{tabular}

(After: [16]); $\mathrm{n}=$ number of samples (100 points). 

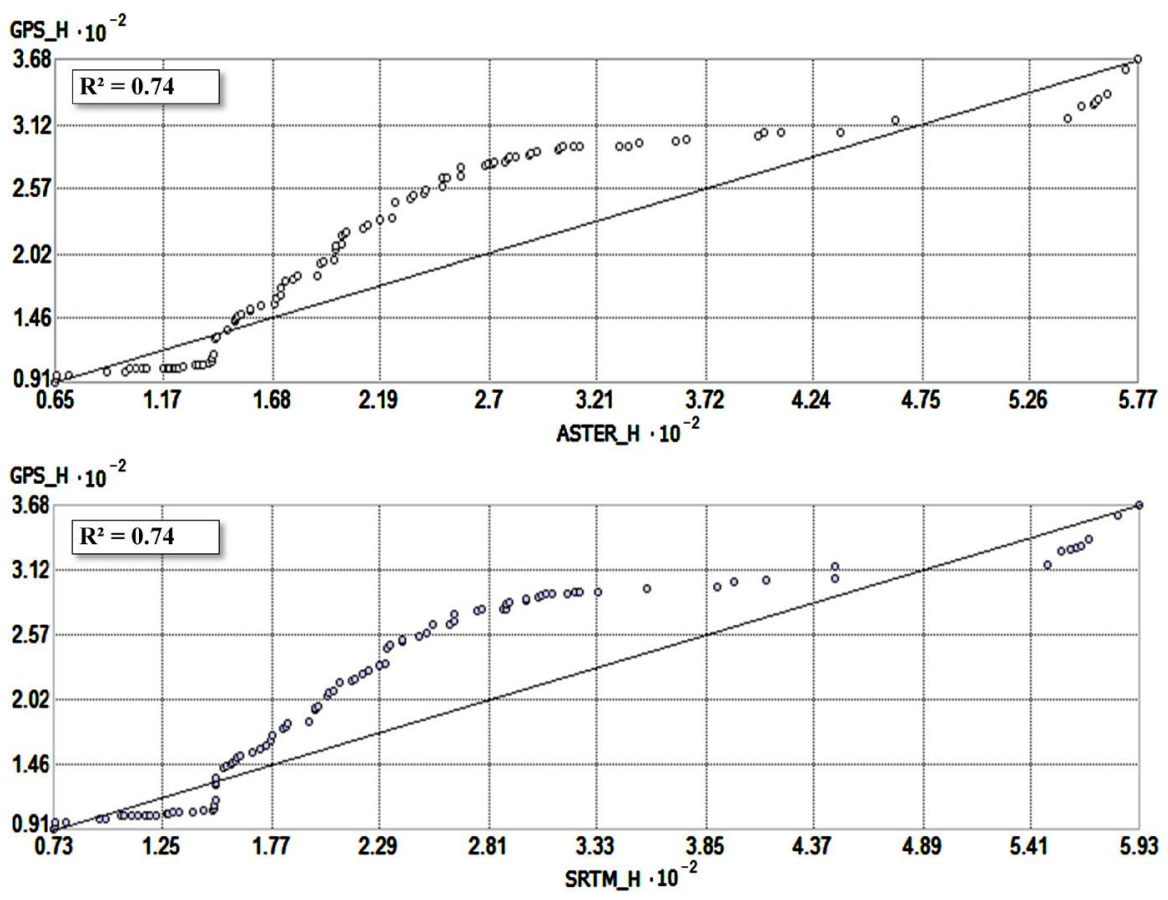

Figure 4. Q-Q plot showing the relationship between reference GPS data and remotely sensed data for the 100 realisations.

Table 2. Error statistics for the remotely sensed DEMs vs. the reference data.

\begin{tabular}{ccccccc}
\hline \multirow{2}{*}{ DEMs } & \multicolumn{3}{c}{$\mathrm{Z}_{\text {dif }}$} & \multirow{2}{*}{ ME } & STD & RMSE \\
\cline { 2 - 4 } & Max. & Min. & Avg. & & & \\
\hline ASTER & 259.5 & -39.8 & 27 & 27.0 & 25 & 75.8 \\
SRTM & 264.7 & -33.2 & 34.2 & 34.2 & 23 & 79.2 \\
\hline
\end{tabular}

deviation of slope and aspect was represented by [26] using the Taylor series and Monte Carlo method. In this section, we used geostatistical standard error propagation, primary constrained derivatives topographic attributes (slope and aspect) and unconstrained derivatives (catchment area and network extraction). Benefit of running an error propagation analysis is, first and foremost, that it quantifies the uncertainty in the GIS result [27].

\subsection{Standard Error Propagation (SE)}

Standard error propagation (SE) of a partial derivative $(\partial Z)$ height(s) quantizes propagation errors of the partial derivative $\partial Z_{D E M}$ from the remotely sensed DEMs with respect to the partial derivative $\partial Z_{\text {ref }}$ from the reference elevation data, where:

$$
\partial(Z)=\sqrt{\partial\left(Z_{D E M}\right)^{2}+\partial\left(Z_{r e f}\right)^{2}}
$$

where $(\partial Z)$ represents the standard deviation of $\mathrm{Z}$. SE assumes that the quantities $a, b$, etc. have uncorrelated and random errors and errors assumed to be spatially uniform. There is a very simple relationship between STD $_{\text {err }}$ and SE which 
can be expressed as:

$$
S E=\frac{S T D_{\text {err }}}{\sqrt{n}}
$$

where $n$ is number of sampled reference data (100). Linear geostatistical analysis of ASTER GDEM and SRTM revealed that both DEMs are highly correlated $\left(\mathrm{r}^{2}\right.$ $=99.62$ ) to each other (Figure 5). Therefore, it is not surprising that error statistical analysis and standard error propagation is very close. The absolute standard error (SE) of the DEMs ranges generally between is $\pm 0-2.5$ and $\pm 0-2.4 \mathrm{~m}$ for ASTER GDEM and SRTM respectively (Figure 6).

Results reveal that the standard deviation of the vertical error has a strong effect on error propagation and this highly obvious in higher elevations. Error visualization shown in Figure 6 depicts that most of the study area (91.7\%) ranges in elevation between $80-320 \mathrm{~m}$ (a.s.l) and only 8.3\% ranges from $320-660 \mathrm{~m}$ (a.s.1). Relatively low laying areas (91.7\%) are less sensitive to error in elevation where SE ranges from 0 - 1.2 and 0 - 1 for ASTER GDEM and SRTM DEMs respectively. Errors in this area mostly associate the upslope areas and it is expected to influence on drainage line and watershed extractions. On the other hand, SE ranges in the higher lands (8.3\%) between $1.2-2.5$ and $1-2.3$ for ASTER GDEM and SRTM DEMs, respectively.

\subsection{Slope and Aspects}

The slope is derived from the first partial derivatives based on the average neighborhood approach (ANS). With the ANS method the slope is estimated by calculating the rate of change in elevation over the distance from the central cell to its eight neighbors using an average maximum approach [28]. Most of GIS Softwares (including the most used ArcGIS) calculates slope plane using a $3 \times 3$ kernel window to determine average rate of change in elevation along lateral

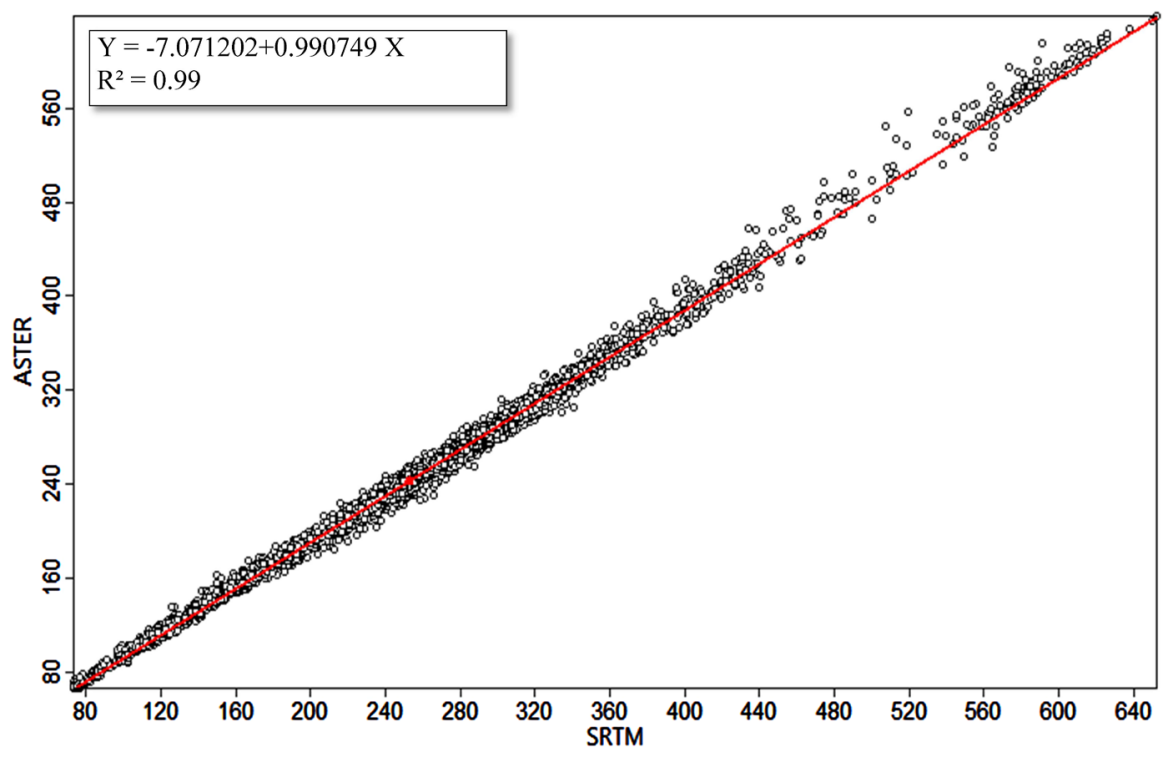

Figure 5. Correlation between ASTER and SRTM DEMs. 

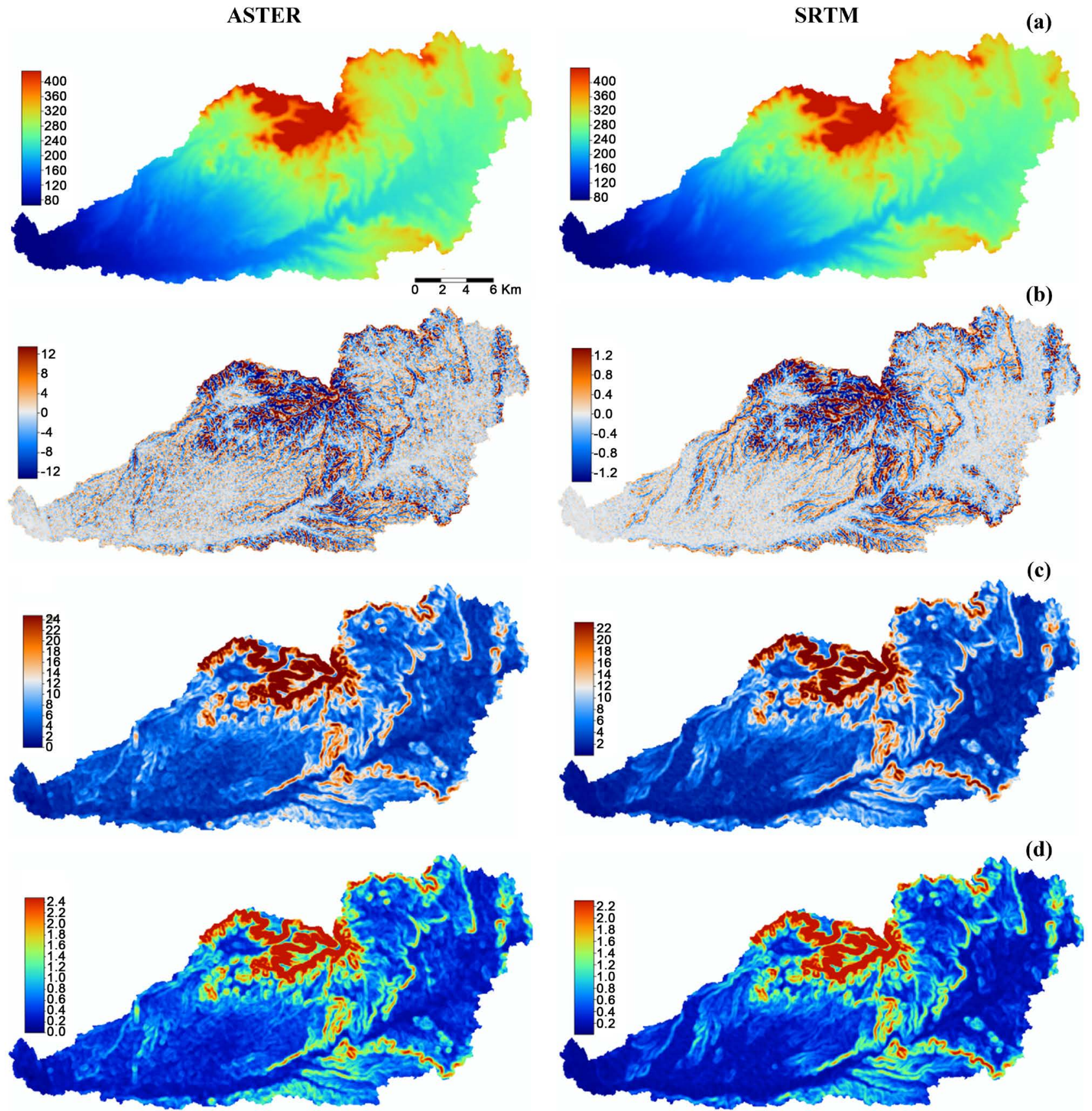

Figure 6. Error visualization: (a) Mean elevation [m]; (b) Differences from mean [m]; (c) Standard deviation; (d) Standard error (SE).

directions $(\delta Z / \delta Y)$ and the horizontal direction $(\delta Z / \delta X)$ from the central cell [29]. In this study the derivate slope $\left(\theta_{\mathrm{deg}}\right)$ was calculated in degrees using ArcGIS software as:

$$
\theta_{\mathrm{deg}}=\operatorname{atan} \sqrt{\left(\frac{\Delta Z}{\Delta X}\right)^{2}+\left(\frac{\Delta Z}{\Delta X}\right)^{2}} \times \frac{180}{p i}
$$

where $\Delta X$ and $\Delta Y$ specify the cell dimensions. The lower the slope value the flatter the terrain; the higher the slope value the steeper the terrain. Table 3 shows 
Table 3. Slope distribution statistics analysis

\begin{tabular}{|c|c|c|c|c|}
\hline \multirow{2}{*}{ DEMs } & \multicolumn{2}{|c|}{ Slope } & \multirow{2}{*}{ STD } & \multirow{2}{*}{ RMSE } \\
\hline & Max. & Avg. & & \\
\hline ASTER & $58.5^{\circ}$ & $6.1^{\circ}$ & $6.2^{\circ}$ & $7.56^{\circ}$ \\
\hline SRTM & $60^{\circ}$ & $4.9^{\circ}$ & $5.66^{\circ}$ & $7.22^{\circ}$ \\
\hline
\end{tabular}

Table 4. Aspect distribution statistics analysis

\begin{tabular}{cccc}
\hline DEMs & Max. & Mean & STD \\
\hline ASTER & $359.9^{\circ}$ & $182.7^{\circ}$ & $102.6^{\circ}$ \\
SRTM & $359.9^{\circ}$ & $187.5^{\circ}$ & $97.2^{\circ}$ \\
\hline
\end{tabular}

that the overall RMSE of slope is $7.56^{\circ}$ and $7.22^{\circ}$ for ASTER GDEM and SRTM, respectively. Slope maps are presented in Figure 7(a) using natural breaks classification (Jenks method) for better visualization since distribution of the slope data is not even. Natural break classification groups cells of the same values and maximize the differences between classes.

Aspect identifies the slope direction or direction of the maximum rate of change elevation from each cell to its neighbors. The values of the output raster will be the compass direction of the aspect. Table 4 shows that the STD is 102.6 for ASTER GDEM and 97.2 for SRTM DEM. The majority of slope aspects face the south-west direction (Figure 7(b), Figure 7(c)).

Magnitude of the DEM errors affects the results of topographic first partial derivatives (slope and aspect). Figure 7(a) \& Figure 7(b) states that slope and aspect errors increasing with the vertical error. Also uncertainty is relatively high in flat area. This may be due to higher variance in DEM and difference of data resolution.

\subsection{Analytical Hillshading}

Analytical hillshading is used to visualize topography as shaded relief. It helps us to immediately determine major topographic reliefs such as ravines, ridges, peaks or valley. Hillshade considers both local illumination angles and shadows. The illumination value for each raster cell is determined by its orientation to the light source. Analytical hillshade was estimated using $315^{\circ}$ sun azimuth and $45^{\circ}$ sun elevation. Results were calculated in radians based on slope and aspect (in radians), and then converted into degrees for better interpretation. The overall STD ranges between $17.7^{\circ}-15.2^{\circ}$ for ASTER GDEM and SRTM DEMs. It is noticeable that the calculated hillshade map from SRTM is less influenced by error propagation than the ASTER GDEM one (Table 5). By zooming into the ASTER's hillshade map, random errors are most conspicuous in flat areas (Figure $7(d)$ ).

\subsection{Automatic Drainage Network Delineation}

ArcGIS Hydro-model was used in this study to automatically extract the drainage 




Figure 7. Primary derivatives topographic attributes: (a) Slope distribution [deg.]; (b) Slope aspect [deg.]; (c) Rose diagram shows aspect distribution by direction; (d) Analytical hillshade.

Table 5. Hillshading distribution statistics analysis

\begin{tabular}{ccccc}
\hline DEMs & Min. & Max. & Mean & STD \\
\hline ASTER & $0.26^{\circ}$ & $83^{\circ}$ & $49.1^{\circ}$ & $17.7^{\circ}$ \\
SRTM & $0.17^{\circ}$ & $76^{\circ}$ & $48.52^{\circ}$ & $15.2^{\circ}$ \\
\hline
\end{tabular}


network and drainage basin. Drainage extraction was done by determining the directions that water will flow out of each cell to its steepest down-slope neighbor (flow direction) relying on the 8D method [30]. Flow accumulation function was applied to tabulate for each cell the number of cells that will flow to it and cells of high flow accumulation were used to identify the trunk channels. Pour point of the main wadi was accurately determined from GPS data by the explicit (x, y) coordinates. Arbitrary threshold value of $\geq 150$ cells was preferred to provide a realistic density of drainage streams [31] [32]. Then, streams were extracted by assigning the flow accumulation layer to integer values $\geq 1$ for a stream and no-data for background. Finally, streams were ordered according to [33].

Investigation of delineated stream networks depicts that automatic drainage basin delineation is very sensitive to DEM uncertainty. This is reflected on many parameters such as flow direction (Table 6), stream number and length (Table 7 ), and their spatial pattern (Figure 8).

Comparison of the spatial patterns of the two extracted drainage networks from ASTER GDEM and SRTM DEMs (Figure 9) reveals poor agreement. Differences have been found to fall in the range between $30-500 \mathrm{~m}$, which means it is highly influenced by DEM resolution and threshold value. However, drainage density and stream frequency reveal relative closeness between the two drainage networks. Since they measure surface dissection and texture of the surface by streams, they are strongly influenced by hill slope processes [34] [35]. Drainage density ranges between $2.7-2.6 \mathrm{~km} / \mathrm{km}^{2}$ and stream frequency is $6.06-5.64$ stream $/ \mathrm{km}^{2}$ for ASTER GDEM and SRTM, respectively.

In the lower part of the drainage basin where relative low lands are dominant, there is unrealistic stream junctions and great changes in stream courses. By zooming into the stream map we observed that some streams are truncated and isolated. Others reveal artificial breaks since they follow the gridded-structure of the DEMs [27].

Table 6. Flow direction statistics analysis

\begin{tabular}{ccccc}
\hline DEMs & Min. & Max. & Mean & STD \\
\hline ASTER & east & northeast & $23.5^{\circ}$ & 32.48 \\
SRTM & east & northeast & 22.5 & 31.9 \\
\hline
\end{tabular}

Table 7. Stream orders statistics analysis

\begin{tabular}{|c|c|c|c|c|c|c|c|c|c|c|c|c|}
\hline \multirow[b]{2}{*}{ DEMs } & \multicolumn{2}{|c|}{1} & \multicolumn{2}{|c|}{2} & \multicolumn{2}{|c|}{3} & \multicolumn{2}{|c|}{4} & \multicolumn{2}{|c|}{5} & \multicolumn{2}{|c|}{6} \\
\hline & $\mathrm{N}$ & $\mathrm{L}$ & $\mathrm{N}$ & $\mathrm{L}$ & $\mathrm{N}$ & $\mathrm{L}$ & $\mathrm{N}$ & $\mathrm{L}$ & $\mathrm{N}$ & $\mathrm{L}$ & $\mathrm{N}$ & $\mathrm{L}$ \\
\hline ASTER & 1304 & 580.7 & 641 & 296.5 & 309 & 132.7 & 207 & 92.7 & 89 & 36.4 & 1 & 11.9 \\
\hline SRTM & 1218 & 554.6 & 558 & 269.8 & 312 & 141.4 & 207 & 98.9 & 77 & 34.4 & 1 & 13.8 \\
\hline Differences & 86 & 26.1 & 83 & 26.7 & -12 & -8.7 & 0 & -6.2 & 12 & 2 & 0 & -1.9 \\
\hline
\end{tabular}

$\mathrm{N}=$ stream number; $\mathrm{L}=$ stream length $[\mathrm{km}]$. 

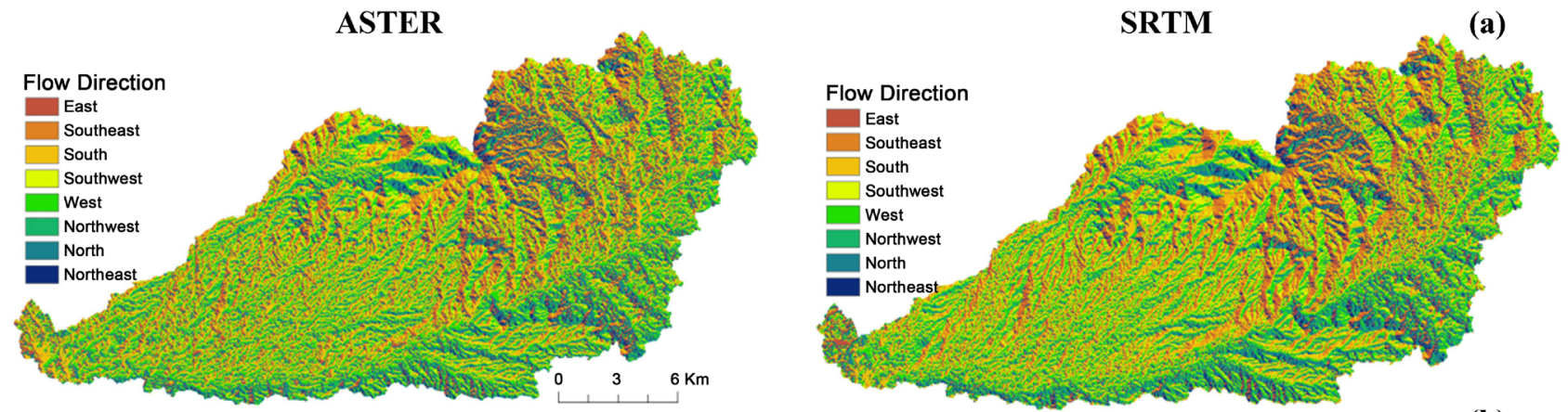

(b)
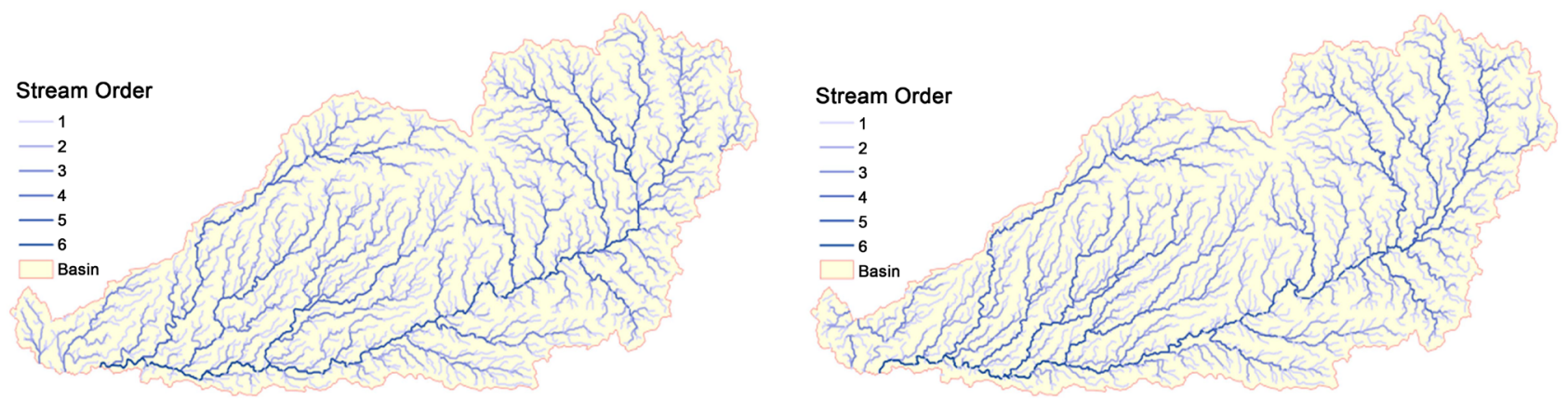

(c)

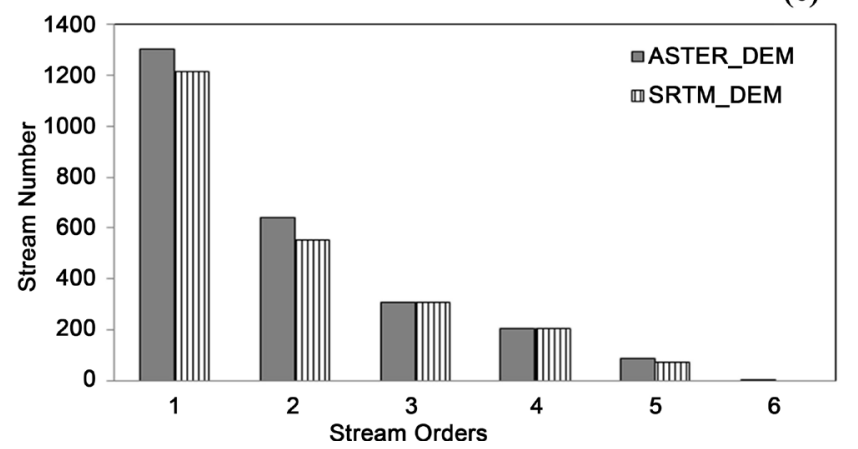

(d)

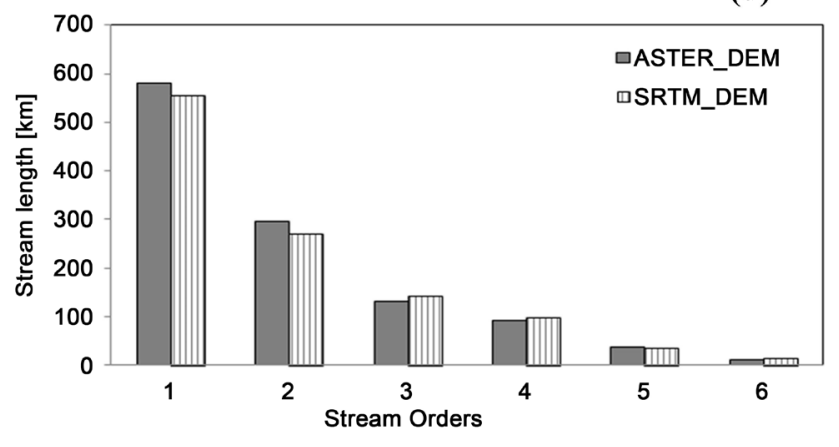

Figure 8. (a) Flow direction; (b) Stream network; (c) Stream numbers ASTER vs. SRTM; stream length [km] ASTER vs. SRTM.

\section{Conclusions}

In this study, we assessed the quality of ASTER GDEM (30 m) and SRTM (90 m) in comparison with in situ DGPS elevation data to reveal its influence on the first derivatives topographic attributes (slope, aspect), topographic representation (hillshading), and the unconstrained derivatives stream networks in a relatively low relief area. Quantifying vertical accuracy is normally achieved by selecting a sample of in situ reference measurements in comparison with the original DEMs data. The vertical accuracy of the two DEMs was calculated using various statistical measurements. The overall absolute vertical accuracy (RMSE) was 75.8 for ASTER GDEM and 79.2 for SRTM (Table 2). That means ASTER GDEM and SRTM DEMs are less accurate than the reference data. This is not surprising since the reference data representing an explicit $\mathrm{x}$ and $\mathrm{y}$ point, while remotely sensed DEMs have a ground resolution of 30 and $90 \mathrm{~m}$ for ASTER GDEM and SRTM DEMs, respectively. In the same context Q-Q plots based on 


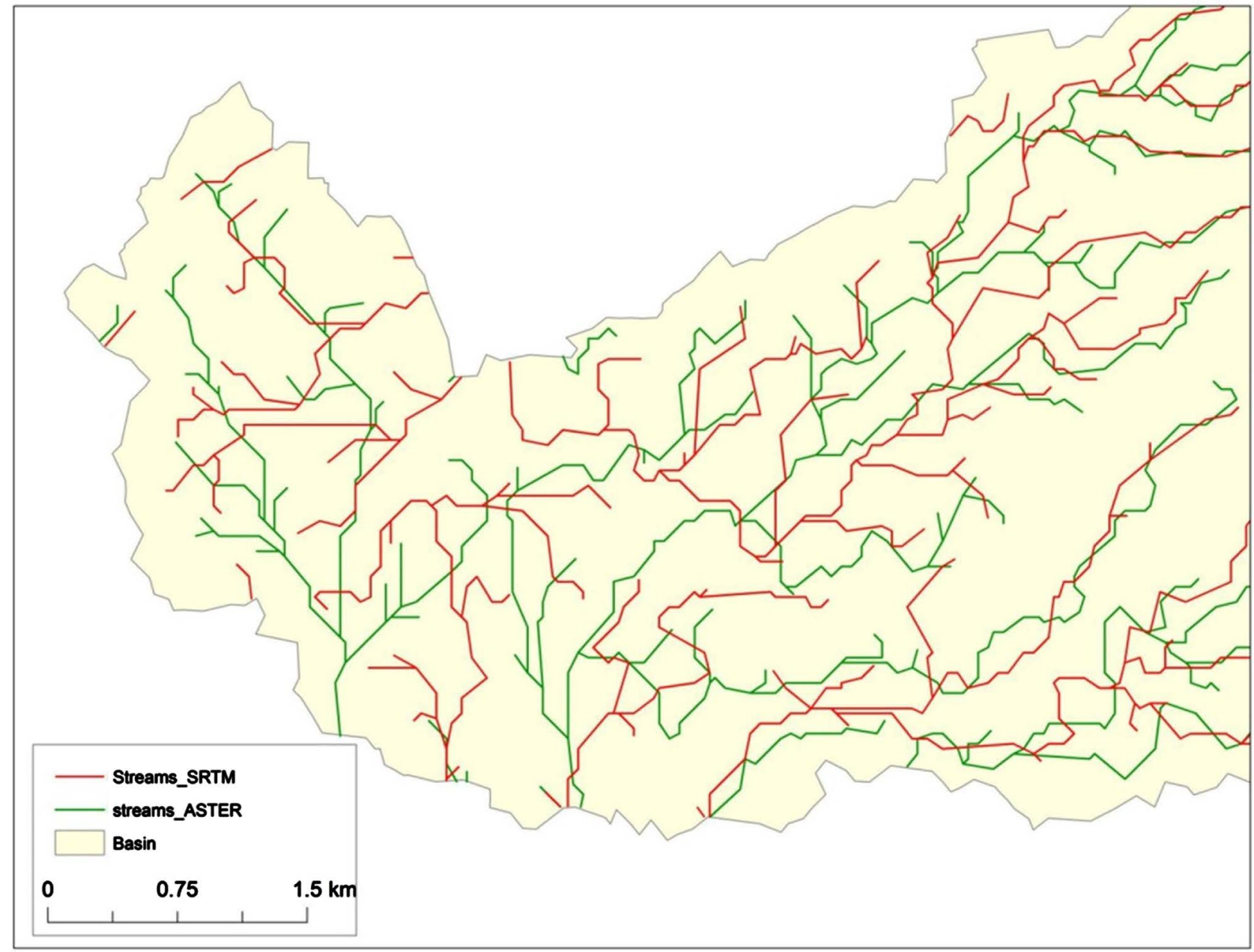

Figure 9. Comparison between extracted stream networks of SRTM vs. ASTER DEMs reveal different spatial pattern, truncated and unrealistic streams.

the normal distribution reveal that the DEMs data are greatly undulated around the best fit linear relationship (Figure 4). That means DEMs data are mostly higher than the corresponding reference GPS data and to some other point samples are relatively lower than the reference data.

Although, linear geostatistical analysis of ASTER GDEM and SRTM revealed that both DEMs are highly correlated $\left(r^{2}=99.62\right)$ to each other, there are slight variations between the two DEMs on the basis of topographic attributes. The absolute standard error (SE) of the DEMs ranges generally between is \pm 0 - 2.5 and $\pm 0-2.4 \mathrm{~m}$ for ASTER GDEM and SRTM respectively (Figure 6). It means that the vertical error has a strong effect on error propagation and this highly obvious in higher elevations $(320-660 \mathrm{~m})$ in the study area and the lower lands $(<320 \mathrm{~m})$ are less sensitive to elevation error. Vertical error influences on drainage line and watershed extractions from the two DEMs. As a result, STD of flow direction ranges from 32.48 for ASTER GDEM and 31.9 for SRTM DEM. It resulted also in the variations between numbers of streams and stream length (Table 7). Error propagation in low lands specifically influences drainage ex- 
traction and resulted in isolated and truncated water courses (Figure 8, Figure 9). To overcome unrealistic stream network and isolated streams (Figure 9), drainage networks were overlaid on an optical remote sensing dataset of Landsat-8 (OLI sensor). We used data fusion technique to increase the spatial resolution from 30 to $15 \mathrm{~m}$ and then stream networks were manually corrected.

However, the overall RMSE of slope is $7.56^{\circ}$ for ASTER GDEM and $7.22^{\circ}$ for SRTM DEM. STD of slope direction is 102.6 for ASTER GDEM and 97.2 for SRTM DEM. Hillshade map extracted from SRTM is less influenced by error propagation than the ASTER GDEM. In brief, it can be concluded that SRTM DEM is relatively closer, accurate and consistent to the reference elevation data in terms of absolute accuracy than ASTER GDEM. On basis of the topographic attributes, there are slight variations between the ASTER GDEM and SRTM DEM.

\section{References}

[1] Fleming, C., Marsh, S.H. and Giles, J.R.A., Eds. (2010) Elevation Models for Geoscience. Geological Society, Special Publications, London, Vol. 345, 148 p.

[2] Guth, P. (2005) Geomorphometry from SRTM: Comparison to NED. In: NASA, The Shuttle Radar Topography Mission: Data Validation and Applications Workshop. 14-16 June, Reston.

[3] USGS, US Geological Survey (1998) Standards for Digital Elevation Models, Part 2: Specifications. http://nationalmap.gov/standards/demstds.html

[4] Vršcaj, B., Daroussin, J. and Montanarella, L. (2007) SRTM as a Possible Source of Elevation Information for Soil-Landscape Modelling. In: Jordan, G., Ed., Digital Terrain Modelling, Springer, 99-120.

[5] Dorey, M. (2002) Digital Elevation Models for Intervisibility Analysis and Visual Impact Assessment. PhD Dissertation, University of Glamorgan, Pontypridd.

[6] Hebeler, F. and Purves, R.S. (2009) The Influence of Elevation Uncertainty on Derivation of Topographic Indices. Geomorphology, 111, 4-16. https://doi.org/10.1016/j.geomorph.2007.06.026

[7] Shi, W., Wang, B. and Liu, E. (2016) Qualitative and Quantitative Comparative Analysis of the Relationship between Sampling Density and DEM Error by Bilinear and Bicubic Interpolation Methods. In: Shi, W., Wu, B. and Stein, A., Eds., Uncertainty Modelling and Quality Control for Spatial Data. CRC Press, Boca Raton, 163-195.

[8] Fisher, P. and Tate, N.J. (2006) Causes and Consequences of Error in Digital Elevation Models. Progress in Physical Geography, 30, 467-489. https://doi.org/10.1191/0309133306pp492ra

[9] Wechsler, S.P. (2007) Uncertainties Associated with Digital Elevation Models for Hydrologic Applications: A Review. Hydrology and Earth System Sciences, 11, 1481-1500. https://doi.org/10.5194/hess-11-1481-2007

[10] Qaid, A.M., Basavarajappa, H.T., Badawy, M.M. and Omo-Irabor, O.O. (2008) A Comparative Analysis of DEM Generated from SRTM Data and Digital Topographic Map: A Case Study of North Eastern Hajjah, Yemen. Journal of Geomatics, Indian Society of Geomatics, 2, 143-147.

[11] Tighe, M.T. and Chamberlain, D. (2009) Accuracy Comparison of the SRTM, ASTER, NED, NEXTMAP USA DTM over Several USA Study Sites. ASPRS/ 
MAPPS 2009 Fall Conference, San Antonia, 16-19 November 2009.

[12] Florinsky, I.V. (2012) Digital Terrain Analysis in Soil and Geology. Elsevier, Amsterdam, $379 \mathrm{p}$.

[13] Kolecka, N. and Kozak, J. (2013) Assessment of the Accuracy of SRTM C- and X-Band High Mountain Elevation Data: A Case Study of the Polish Tatra Mountains. Pure and Applied Geophysics, 171, 897-912.

[14] Czubski, K., Kozak, J. and Kolecka, N. (2013) Accuracy of SRTM-X and ASTER Elevation Data and Its Influence on Topographical and Hydrological Modeling: Case Study of the Pieniny Mts. in Poland. International Journal of Geoinformatics, 9, 7-14.

[15] Athmania, D. and Achour, H. (2014) External Validation of the ASTER GDEM2, GMTED2010 and CGIAR-CSI-SRTM v4.1 Free Access Digital Elevation Models (DEMs) in Tunisia and Algeria. Remote Sensing, 6, 4600-4620. https://doi.org/10.3390/rs6054600

[16] Pakoksung, K. and Takagi, M. (2016) Digital Elevation Models on Accuracy Validation and Bias Correction in Vertical Model. Earth Systems and Environment, 2, 11. https://doi.org/10.1007/s40808-015-0069-3

[17] Gesch, D., Oimoen, M., Zhang, Z., Danielson, J. and Meyer, D. (2011) Validation of the ASTER Global Digital Elevation Model (GDEM) Version 2 over the Conterminous United States. U.S. Geological Survey, Earth Resources Observation Science (EROS) Center, Sioux Falls.

[18] NASA (2015) The Shuttle Radar Topography Mission (SRTM) Collection User Guide. 17 p.

[19] Foni, A. and Seal, D. (2004) Shuttle Radar Topography Mission: An Innovative Approach to Shuttle Orbital Control. Acta Astronautica, 54, 565-570. https://doi.org/10.1016/S0094-5765(03)00227-3

[20] El-Rabban, A. (2000) Introduction to GPS. Artech House, London, 195 p.

[21] Forkuor, J. and Maathuis, B. (2012) Comparison of SRTM and ASTER Derived Digital Elevation Models over Two Regions in Ghana-Implications for Hydrological and Environmental Modeling. In: Piacentini, T. and Miccadei, E., Eds., Studies on Environmental and Applied Geomorphology, InTech, London, Chapter 9, 219-240.

[22] Santillan, J.R. and Santillan, M.M. (2014) Detection and Correction of ASTER GDEM v2 Data Anomalies. 35th Asian Conference on Remote Sensing (ACRS 2014), Nay Pyi Taw, Vol. 2, 1261-1266.

[23] Pedrera, A., Pérez-Peña, J.V., Galindo-Zaldívar, J., Azañón, J.M. and Azor, A. (2009) Testing the Sensitivity of Geomorphic Indices in Areas of Low-Rate Active Folding (Eastern Betic Cordillera, Spain). Geomorphology, 105, 218-231. https://doi.org/10.1016/j.geomorph.2008.09.026

[24] Bolstad, P.V. and Stowe, T. (1994) An Evaluation of DEM Accuracy: Elevation, Slope, and Aspect. Photogrammetric Engineering and Remote Sensing, 60, 13271332.

[25] Lane, S.N., Ames, J.T.D. and Rowell, M.D. (2000) Application of Digital Photogrammetry to Complex Topography for Geomorphological Research. The Photogrammetric Record, 16, 793-821. https://doi.org/10.1111/0031-868X.00152

[26] Heuvelink, G.B.M., Burrough, P.A. and Leenaers, H. (1990) Error Propagation in Spatial Modelling with GIS. Proceedings of the 1 st European Conference on Geographical Information Systems, Amsterdam, 10-13 April 1990, 453-462. 
[27] Hengl, T., Heuvelink, G.B.M. and van Loon, E.E. (2010) On the Uncertainty of Stream Networks Derived from Elevation Data: The Error Propagation Approach. Hydrology and Earth System Sciences, 14, 1153-1165. https://doi.org/10.5194/hess-14-1153-2010

[28] Burrough, P. and McDonnell, R. (1998) Principles of Geographical Information Systems. Oxford University Press, Oxford.

[29] Irfan, A.M., Zhao, Z., Bourque, C.P.-A. and Meng, F.-R. (2012) GIS-Evaluation of Two Slope Calculation Methods Regarding Their Suitability in Slope Analysis Using High-Precision LiDAR Digital Elevation Models. Hydrological Processes, 26, 1119-1133. https://doi.org/10.1002/hyp.8195

[30] O'callaghan, J.F. and Mark, D.M. (1984) The Extraction of Drainage Networks from Digital Elevation Data. Computer Vision, Graphics Image Process, 28, 323-344. https://doi.org/10.1016/S0734-189X(84)80011-0

[31] Badawy, M.M. (2013) Analysis of the Flash Flood Occurred on $18^{\text {th }}$ January 2010 in Wadi El Arish, Egypt (A Case Study). Geomatics Natural Hazards and Risk, 4, 254-274.

[32] Badawy, M.M., Abdel Aziz, A.O. and Mamtimin, B. (2016) Flash Floods in the Sahara: A Case Study for the 28th January 2013 Flood in Qena-Egypt. Geomatics Natural Hazards and Risk, 7, 215-223.

[33] Strahler, A.N. (1957) Quantitative Analysis of Watershed Geomorphology. Transactions-American Geophysical Union, 38, 913-920. https://doi.org/10.1029/TR038i006p00913

[34] Tucker, G.E. and Bars, R.L. (1998) Hillslope Processes, Drainage Density and Landscape Morphology. Water Resources Research, 34, 2751-2764.

[35] Badawy, M.M. (2008) Applications of Remote Sensing and Geographic Information Systems in Geomorphological Studies: Safaga-El Quseir Area, Red Sea, Egypt as an Example. VDM Verlag Dr. Müller, Saarbrücken, 282. 